\title{
Using fire to promote biodiversity
}

\section{Submitted version}

\author{
Authors: L.T. Kelly ${ }^{1 *}$, L. Brotons ${ }^{2}$
}

\begin{abstract}
Affiliations:
${ }^{1}$ School of BioSciences, ARC Centre of Excellence for Environmental Decisions, University of Melbourne, Parkville, Victoria 3125, Australia.

${ }^{2}$ InForest Joint Research Unit, Centre for Mediterranean Forest Research - Forest Sciences Centre of Catalonia, 25280 Solsona, Spain.

*Correspondence to: 1tkelly@unimelb.edu.au
\end{abstract}

The final version is available from the corresponding author (ltkelly@unimelb.edu.au) or via https://www.sciencemag.org/ and should be cited as:

Kelly, L.T., Brotons, L (2017) Using fire to promote biodiversity. Science, 355, 1264-1265. 


\title{
Title: Using fire to promote biodiversity
}

\author{
Authors: L.T. Kelly ${ }^{1 *}$, L. Brotons ${ }^{2}$
}

\author{
Affiliations: \\ ${ }^{1}$ School of BioSciences, ARC Centre of Excellence for Environmental Decisions, University of \\ Melbourne, Parkville, Victoria 3125, Australia. \\ ${ }^{2}$ InForest Joint Research Unit, Centre for Mediterranean Forest Research - Forest Sciences \\ Centre of Catalonia, 25280 Solsona, Spain. \\ *Correspondence to: 1tkelly@ unimelb.edu.au
}

One Sentence Summary: Biodiversity can benefit from fires that are tailored to suit the needs of particular ecosystems and species.

\section{Main Text:}

All around the world fire is profoundly influencing people, climate, and ecosystems (1). And the impacts of this interaction are likely to grow with climate models forecasting widespread increases in fire frequency and intensity because of increasing global temperatures (2). The survival of many plant and animal species depends on understanding how fire affects biodiversity (3), but addressing this component of the "worldwide wildfire problem" is complex (4). On one hand, many plants and animals require fire for their survival. On the other, even within fire-prone ecosystems, some species and communities are highly sensitive to fire. How then, can a fire regime support the conservation of species with different requirements? And how can we achieve this in a rapidly changing world?

An appealing and influential concept in ecology is that more diverse environments tend to have higher biodiversity (5). In the context of fire and biodiversity, this concept has encouraged diversity in fire regimes under the hypothesis that "pyrodiversity promotes biodiversity" (6). This hypothesis posits that increasing spatial and temporal variation in fires produces a greater 
variety of ecological niches and therefore supports the coexistence of more species $(6)$. This idea is only now being tested at large scales.

In a recent paper, Tingley et al. (3) significantly advanced understanding of pyrodiversity by analyzing how variation in fire history shapes bird diversity in conifer forests of California, USA. They collected an outstanding data set of $>38,000$ observations of birds, sampled across $>1000$ sites and 97 fires that varied in time since the last fire and burn severity. Bird diversity increased with pyrodiversity - fires with greater variation in burn severity had more species and this effect increased in the decade following fire. Different burn severities created unique habitats, including areas with low and high cover of trees, whose bird communities differed over time (3). Some species in this region, such as the black-backed woodpecker, are dependent on habitat created by severe burns (7). Tingley et al. provide strong evidence that conifer forests with high variation in fire severity, a type of forest fire reduced by a legacy of fire suppression, are critical for sustaining biodiversity.

Another recent study also demonstrates that more species occur in areas with a high diversity of fire histories. Ponisio et al. (5) collected $>7000$ pollinator specimens, from 71 flowering plants species, in sites representing variation in fire interval and burn severity in conifer forests of Yosemite National Park, California. The number of unique pollinator visits to flowering plants was positively associated with increasing pyrodiversity, in correspondence with higher diversity of both pollinators and plants in areas with higher variation in fire interval and severity. This study is further evidence that variation in fire regimes supports the coexistence of more species in conifer forests and, importantly, it indicates that pyrodiversity can promote biodiversity through interactions across trophic levels (5). 
However, it is more complex than simply saying that more variety equals better biodiversity outcomes. Determining the amount and type of pyrodiversity appropriate to different ecosystems remains essential because some studies show that increasing variation in fire regimes does not necessarily increase biodiversity. In semi-arid eucalypt woodlands of Australia, for example, the diversity of birds was not correlated with increasing spatial variation in pyrodiversity (8). In eucalypt woodlands, Berry et al. (9) found that large patches of long-unburnt vegetation have particularly high levels of bird diversity because they contain critical food and shelter resources, such as large trees, that support many species. Together, recent studies by Tingely et al., Ponisio et al. and Berry et al. show that it is important to consider how fire influences both the diversity and area of suitable habitat across a suite of species $(3,5,9)$.

While increasing pyrodiversity does not necessarily increase biodiversity in all ecosystems, research on fire-driven variation is proving valuable in developing new, theory-based approaches for determining fire patterns that support biodiversity (10). For example, plant life-history traits including the time to reproductive maturity and senescence can help estimate lower and upper limits of intervals between fires that best support species with different requirements (11). Identifying appropriate limits for other characteristics of fires, such as severity and patch size, is in its infancy. This is another reason why new research by Tingley et al. and others is important. By quantifying relationships between pyrodiversity and biodiversity we can begin to define "bounded ranges of variation" for multiple characteristics of fires (12), tailored to support particular ecosystems and species (figure).

But fire and biodiversity cannot be understood in isolation from other drivers of environmental change. Enright et al. (2) recently showed that a hotter, drier climate will reduce the range of fire intervals that allows plants to persist. This "interval squeeze" is caused by changing levels of 
moisture under climate change that influence plant growth and reproduction; and has the potential to alter ecosystem structure (2). Plant species particularly vulnerable to interval squeeze are those dependent on canopy stored seeds for population recovery after fire. This includes species from iconic families of shrubs, such as Hooker's banksia (Proteaceae), found in biodiversity hotspots in Australia and South Africa (2). Clearly, linking plant and animal relationships with pyrodiversity also requires an understanding of feedbacks between fire regimes, biodiversity and ecosystems (10).

Fire-prone ecosystems are changing in other ways. Urbanization in southern Australia and western USA, regrowth of forests on abandoned land in Europe's northern Mediterranean, deforestation in tropical South America and Asia, and invasive plants in South Africa are all radically modifying fire regimes and biodiversity $(1,4,11,13)$. Developments in fire ecology reported here provide researchers with new avenues to couple models of animal and plant responses to fire with landscape simulations and scenarios analyses to make predictions of biodiversity change in these complex landscapes. Rapid progress in the development of models and decision tools, including through global efforts such as the Intergovernmental Science-Policy Platform on Biodiversity and Ecosystem Services (IPBES), is also helping to make better choices about when and where to conduct planned burning and fire suppression, while considering uncertainties such as the occurrence of wildfires and droughts (8).

These new tools and approaches are progressively being put to work by land managers and policy makers $(1,4,8)$. One practical challenge is to integrate the growing scientific knowledge of pyrodiversity-biodiversity relationships with valuable place-based knowledge of fire held by people. Pyrodiversity has been connected to traditional burning by indigenous people in Australia and North America, and farmers in Europe and tropical savanna $(6,10,13)$. For 
example, research in the deserts of Western Australia is providing insights into how Aboriginal hunting fires support the coexistence of multiple species by generating variation in the size of unburnt patches (13). Moreover, partnerships between scientists and indigenous land owners in savanna landscapes of Arnhem Land, northern Australia, is showing how use of fire that incorporates traditional practices (e.g. implementing cool, patchy burns) and contemporary practices (e.g. aerial planned burning) can achieve multiple objectives including biodiversity conservation and reduction in greenhouse-gas emissions (14).

Another practical challenge is management when there is uncertainty about biodiversity responses to fire. Adaptive fire management of highly flammable savannas of Kruger National Park, South Africa, points to a way forward in applying research (15). Here, fire management in landscapes supporting grazing animals such as elephants, sable antelope and zebra has been designed to achieve ecological objectives defined by bounded ranges of variation (or thresholds) in the area and intensity of fires. This adaptive approach is underpinned by experimental manipulation of alternative fire regimes and a framework involving ongoing research, monitoring and evaluation. One measure of success is that fire management policy in Kruger NP changed as understanding of fire expanded (15).

A surge of new work has advanced knowledge of how spatial and temporal variation of fire influences biodiversity but there is a need to further develop approaches that are better tailored to local conditions. The identification of critical limits or thresholds in patterns of fires that support particular taxa and ecosystems, and how these vary among different and changing landscapes, remain outstanding questions requiring further research. Large-scale data on fire and biodiversity are becoming increasingly available, creating tremendous opportunities for cross-continental comparisons. There is now an exciting opportunity to narrow the gap between current fire 
management and fast-growing knowledge of plant and animal interactions with fire. New and interdisciplinary approaches involving ecologists, climate and fire modellers, scenario planners and social scientists will help to ensure we better understand and use fire to promote biodiversity.

\section{References and Notes:}

1. M. A. Moritz, E. Battlori, R. A. Bradstock, A. M. Gill, J. Handmer, P.F. Hessburg, J. Leonard, S. McCaffrey, D.C. Odion, T. Schoennagel, A. D. Syphard, Learning to coexist with wildfire. Nature. 515, 58-66 (2014).

2. N. J. Enright, J. B. Fontaine, D. M. J. S. Bowman, R. A. Bradstock, R. J. Williams, Interval squeeze: altered fire regimes and demographic responses interact to threaten woody species persistence as climate changes. Front. Ecol. Environ. 13, 265-272 (2015).

3. M. W. Tingley, V. Ruiz-Gutiérrez, R. L. Wilkerson, C. A. Howell, R. B. Siegel, Pyrodiversity promotes avian diversity over the decade following forest fire. Proc. R. Soc. B. 283 doi:10.1098/rspb.2016.1703 (2016).

4. A. M. Gill, S. L. Stephens, G. J. Cary, The worldwide "wildfire" problem. Ecol. Appl. 23, 438-454 (2013).

5. L. C. Ponisio, K. Wilkin, L. K. M'Gonigle, K. Kulhanek, L. Cook, R. Thorp, T. Griswold, C. Kremen, Pyrodiversity begets plant-pollinator community diversity. Glob. Chang. Biol. 22, 1794-1808 (2016).

6. R. E. Martin, D. B. Sapsis, "Fires as agents of biodiversity: pyrodiversity promotes biodiversity" in Proceedings of the Symposium on Biodiversity in Northwestern California, H. Kerner, Ed. (Wildland Resources Centre, University of California, 1991), pp. 150-157. 
7. R. L. Hutto, R. E. Keane, R. L. Sherriff, C. T. Rota, L. A. Eby, V. A. Saab, Towards a more ecologically informed view of severe forest fires. Ecosphere 7, e01255 (2016).

8. L. T. Kelly, L. Brotons, M. A. McCarthy, Putting pyrodiversity to work for animal conservation. Conserv. Biol., doi:10.1111/cobi.12861 (2016).

9. L. E. Berry, D. B. Lindenmayer, D. A. Driscoll, Large unburnt areas, not small unburnt patches, are needed to conserve avian diversity in fire-prone landscapes. J. Appl. Ecol. 52, 486-495 (2015).

10. D. M. J. S. Bowman, G. L. W. Perry, S. I. Higgins, C. N. Johnson, S. D. Fuhlendorf, B. P. Murphy, Pyrodiversity is the coupling of biodiversity and fire regimes in food-webs. Philos. Trans. R. Soc. Lond. B. Biol. Sci. 371, 20150169 (2016).

11. J. E. Keeley, W. J. Bond, R. A. Bradstock, J. G. Pausas, P. W. Rundel, in Fire in Mediterranean Ecosystems: Ecology, Evolution and Management (Cambridge University Press, 2012).

12. M. A. Moritz, M. D. Hurteau, K. N. Suding, C. M. D’Antonio, Bounded ranges of variation as a framework for future conservation and fire management. Ann. N. Y. Acad. Sci. 1286, $92-$ 107 (2013).

13. C. I. Roos, A. C. Scott, C. M. Belcher, W. G. Chaloner, J. Aylen, R. Bliege Bird, M. R. Coughlan, B. R. Johnson, F. H. Johnston, J. McMorrow, T. Steelman, Fire and Mankind Discussion Group, Living on a flammable planet: interdisciplinary, cross-scalar and varied cultural lessons, prospects and challenges. Philos. Trans. R. Soc. B Biol. Sci. 371, 20150469 (2016). 
14. J. Russell-Smith, G. D. Cook, P. M. Cooke, A. C. Edwards, M. Lendrum, C. P. Meyer, P. J. Whitehead, Managing fire regimes in north Australian savannas: applying Aboriginal approaches to contemporary global problems. Front. Ecol. Environ. 11, e55-e63 (2013).

15. B. W. van Wilgen, N. Govender, I. P. J. Smit, S. MacFadyen, The ongoing development of a pragmatic and adaptive fire management policy in a large African savanna protected area. $J$. Environ. Manage. 132, 358-368 (2014). 
Fig. 1.

\section{Connecting pyrodiversity to biodiversity}

Biodiversity can benefit from variation in fire regimes tailored to suit the needs of particular ecosystems and species.

\section{Spatial variation of fire}

Knowing how animals are influenced by the diversity, size and arrangement of fire attributes, such as fire severity, can guide conservation management. The role of biotic interactions, including plant-pollinator relationships, is also an important consideration.

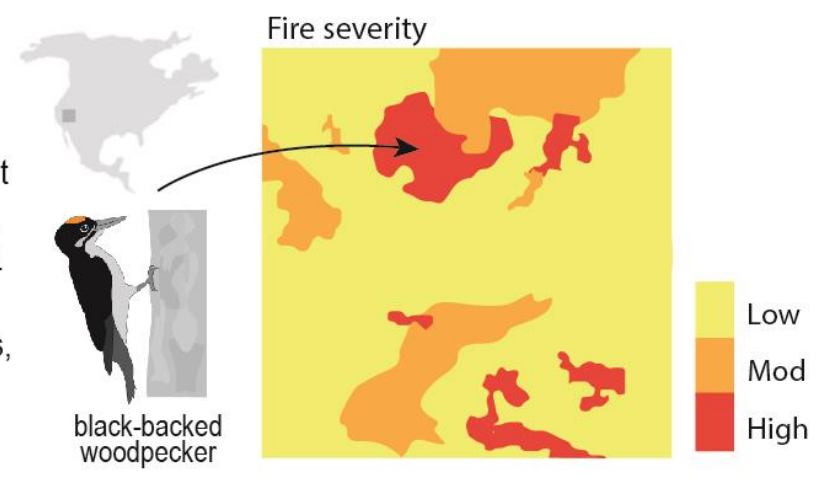

\section{Temporal variation of fire}

Life-history traits of plants, including time to reproductive maturity and senescence, can be used to estimate lower and upper bounds of fire intervals that support biodiversity. In some ecosystems, a drier climate is reducing the range of fire intervals that allow plants to persist.

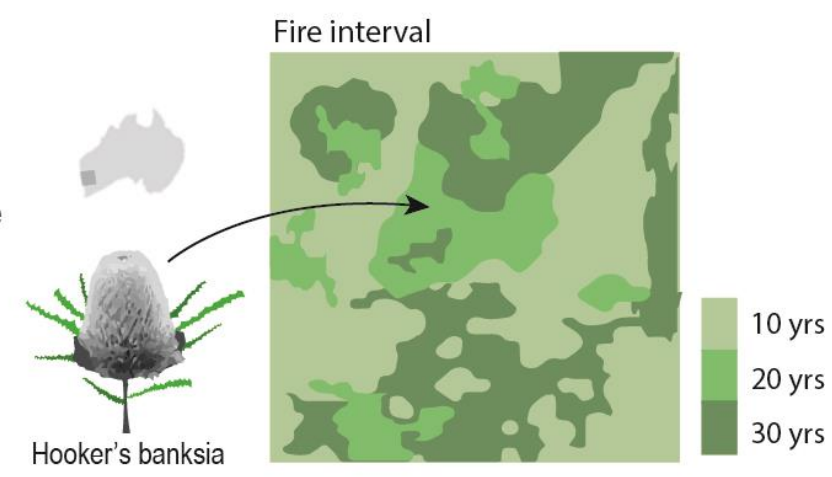




\section{Photo}

Planned burning in Albacete, east-central Spain (C. Vilarasau, Pau Costa Foundation)

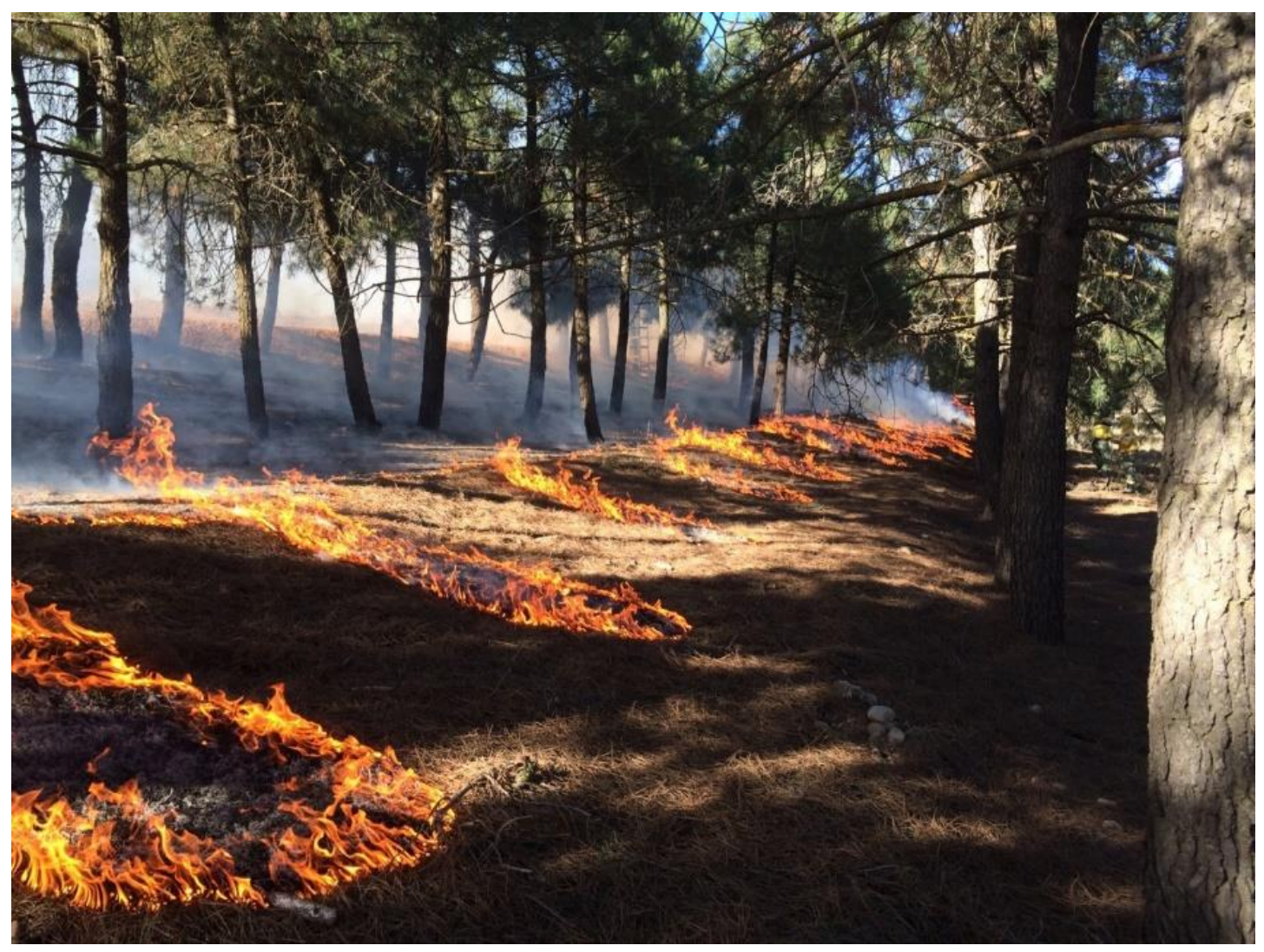

